\title{
Iluminismo e absolutismo no modelo jurídico-penal de Cesare Beccaria
}

\begin{abstract}
Arno Dal Ri Júnior*
Alexander de Castro**

Sumário: Introdução; 1. Iluminismo e absolutismo: o reformismo habsbúrgico na Lombardia da metade do século XVIII; 2. Um projeto de Direito Penal para o absolutismo esclarecido: o utilitarismo em Dei Delitti e delle Pene. Conclusão. Referências.
\end{abstract}

\begin{abstract}
Resumo: Cesare Beccaria, tido como o autor que, elaborando um sistema de direito penal com base em princípios iluministas, criou as bases do moderno direito penal de cunho liberal, possuía, entretanto, vínculos muito profundos com o absolutismo austríaco. Assim, no presente trabalho, analisaremos alguns pontos da tessitura política em que Beccaria produziu a obra Dei Delitti e delle Pene, procurando aprofundar a compreensão sobre o modo como o Iluminismo, no contexto de formação do absolutismo habsbúrgico, funcionaria na elaboração do modelo jurídico-penal do jurista italiano.
\end{abstract}

Palavras-chave: Beccaria; Direito Penal; Iluminismo; Absolutismo Esclarecido.

\begin{abstract}
Cesare Beccaria, known as the author who, elaborating a system of criminal law based on illuminists principles, has created the bases of the modern liberal criminal law, had, however, very deep bonds with the Austrian absolutism. Thus, in the present paper, we will analyze some points of the politic structure where Beccaria produced his work Dei Delitti e delle Pene, seeking to examine the understanding about the way Illuminism, in the context of the Habsburg absolutism's formation, would operate in the elaboration of the Italian jurist's legal criminal model.
\end{abstract}

Keywords: Beccaria; Criminal Law; Illuminism; Enlightened Absolutism.

\section{Introdução}

O nome de Cesare Beccaria figura entre aqueles autores tidos como clássicos dentro da história do direito. Sua importância deve-se ao fato de ser ele considerado o principal marco da inserção das idéias e dos princípios da filosofia do Iluminismo no âmbito do saber jurídico-penal, o que permite colocá-lo entre os pioneiros da cons-

\footnotetext{
* Doutor em Direito pela Università Luigi Bocconi de Milão, com Pós-doutorado pela Université Paris I (Panthéon-Sorbonne). Mestre em Direito pela Università degli studi di Padova. Professor nos cursos de Graduação e Pós-Graduação em Direito da Universidade Federal de Santa Catarina.

** Mestre em Direito pelo Curso de Pós-Graduação em Direito da UFSC (CPGD/UFSC). Professor de Direito Penal da Universidade Federal de Santa Catarina e de Filosofia do Direito do Cesusc-São José.
} 
trução da modernidade jurídica. De tal forma, a imagem um tanto estereotipada e imprecisa que geralmente compõe as concepções mais apressadas da Ilustração do século XVIII acaba muitas vezes contaminando a interpretação de sua obra e desviando a atenção dos estudiosos do direito penal para aspectos que dizem respeito muito mais à glorificadora auto-imagem que de si faz a modernidade do que às questões nas quais o jurista italiano efetivamente encontrava-se envolvido. Conseqüentemente, quando dele se fala nos tradicionais manuais de direito penal tem-se em conta, normalmente, seu papel de "corajoso defensor da humanidade", que teria contribuído para limpar a Europa do "banho de sangue" no qual estaria imersa, colocando assim a repressão penal em conformidade com aqueles princípios filosóficos materializados na Revolução Francesa.

Por outro lado, a literatura de teor crítico sobre direito penal procurou muitas vezes enxergar em Beccaria e em seus vínculos com o liberalismo que então se afirmava (vínculos que freqüentemente são exagerados na bibliografia especializada) a tranqüila defesa de um modelo que, do cume das estruturas políticas do Estado liberal até ao braço da repressão penal, garantiria, sem mais, o moderno domínio "burguês" sobre o conjunto da sociedade. Beccaria é, assim, glorificado ou criticado por posicionamentos políticos que, muito embora possuíssem conexões com seu contexto, não diziam respeito ao cerne dos embates políticos com que se confrontava em sua patriciesca Milão da década de 60 do século XVIII, em que a possibilidade da ascensão de uma pura hegemonia burguesa não era sequer sonhada. De tal maneira, a análise do papel e da importância de Beccaria para uma das etapas da formação do direito penal moderno, para que possa auxiliar em uma maior compreensão do fenômeno jurídico-penal e informar de maneira mais certeira seu viés crítico, deve afiar as lâminas com as quais corta os complexos históricos e voltar-se para a teia das formações sociais na qual nosso autor se encontrava.

Cesare Beccaria escreve Dei Delitti e delle Pene entre o final de 1763 e o início de 1764, publicando-a nos primeiros meses desse ano. Beccaria residia em Milão, o centro da Lombardia, região que desde a guerra da sucessão espanhola fazia parte dos domínios da monarquia austríaca. O jovem marquês contava então apenas 26 anos e fazia parte de um grupo de jovens intelectuais que lia entusiasticamente os autores do Iluminismo francês e que, escrevendo a partir de suas idéias, fixaria definitivamente a filosofia iluminista na Lombardia austríaca. Ao mesmo tempo, a coroa austríaca, em meio a seu projeto político autocrático, implementava em seus domínios um potente programa de reformas que tendia à racionalização da administração e à maximização da eficiência administrativa, e que, na medida em que se chocava frontalmente com interesses nobiliárquicos, acabaria exercendo na Lombardia um papel modernizador. O progressivo suces- 
so de tal projeto, aliado à ausência de quaisquer outras tendências suficientemente fortes que elaborassem as pressões por mudanças sob formas mais ousadas (como no caso da Inglaterra do século XVII), canalizou os interesses progressistas mais conseqüentes em favor do projeto do absolutismo austríaco. O Iluminismo lombardo não seria exceção.

$\mathrm{Na}$ Alemanha e em especial na Prússia, a filosofia do Iluminismo nasce e se desenvolve muito próxima ao absolutismo e à reflexão pró-absolutista. Na França, diferentemente, o Iluminismo teve sempre uma relação ambivalente com o absolutismo, que em parte foi causada pela própria indisposição da coroa francesa em implementar um programa de reformas que atacasse decisivamente os poderes estamentais e que ao mesmo tempo incorporasse as tendências modernizadoras que provinham de determinados setores da sociedade. Esta relação ambivalente do Iluminismo francês com o absolutismo aparece nas páginas de alguns dos grandes autores da França das décadas de 50, 60 e 70 do século XVIII, onde o flerte com o absolutismo, baseado na esperança de que a coroa pudesse vir a aprofundar seu papel modernizador, atacando com mais firmeza o poder nobiliárquico e realizando as reformas desejadas, tal como acontecia na Prússia com Frederico II, dividia espaço com os ecos das idéias liberais da Inglaterra que, nas penas dos iluministas franceses, davam origem a concepções políticas de orientação republicana e, por vezes, até democrática. O Iluminismo lombardo desenvolve-se tendo como referência e inspiração os autores franceses, mas na construção de seu Iluminismo os intelectuais da Lombardia confrontavam-se com uma situação política e social consideravelmente diferente da francesa. $\mathrm{O}$ fato de a coroa austríaca ter incorporado em seu projeto absolutista um programa de reformas que romperia o poder patrício, fomentaria o desenvolvimento econômico e modernizaria as instituições fez com que as tendências próabsolutistas do Iluminismo lombardo, que estavam presentes já em suas matrizes francesas, se desenvolvessem com toda força.

Nos escritos dos autores iluministas despontava com relativa importância a chamada questão penal ${ }^{1}$ como um capítulo dentro da construção teórica do Estado moderno. A obra Dei Delitti e delle Pene foi certamente a mais significativa dentre as que, no seio da Filosofia das Luzes, ocuparam-se com o direito penal e viria a marcar, assim, boa parte do debate sobre o tema. Na época de sua publicação, a

\footnotetext{
1 "Forse in nessun periodo come nella seconda metà del XVIII secolo è stato intensamente dibattuto il problema penale. Per 'problema penale' si intende un complesso di problemi tra loro conessi, di cui è difficile presentare una lista completa" (TARELLO, Giovanni. Il "problema penale" nel secolo XVIII. In: TARELLO, Giovanni (org.). Materiali per una Storia della Cultura Giuridica. Vol. V. Genova: Il Mulino, 1975, p. 15).
} 
dinastia habsbúrgica preparava-se, depois de uma breve interrupção, para aprofundar decisivamente sua política de reformas na Lombardia, uma política que, ao fim do governo de José II, criaria ali outro mundo. Escrita na juventude do filósofo, num período em que o grupo dos jovens iluministas de Milão reunido na chamada Società dei Pugni lutava para afirmar-se no cenário político, inserindo-se, com seu periódico Il Caffè, nos debates públicos mais importantes da época, ao mesmo tempo em que se encantava com os novos horizontes trazidos pelo reformismo habsbúrgico, Dei Delitti e delle Pene retrataria com profundidade os planos e as esperanças que orientaram a formação do Iluminismo na Lombardia. O projeto de sistema penal elaborado por Beccaria pode revelar muito sobre como a empreitada política do absolutismo tardio do século XVIII era vista pelo Iluminismo, sobre quais eram os desafios que a formação desse absolutismo teria de enfrentar e, principalmente, sobre o papel do direito penal na dinâmica institucional do século XVIII. Além de tudo isso, Dei Delitti e delle Pene marcou a inserção do Iluminismo lombardo no mapa da cultura ilustrada da Europa do século XVIII, fazendo com que o continente voltasse um pouco de sua atenção para o que escreviam os jovens patrícios de Milão.

No presente artigo tentaremos analisar alguns pontos dentro da tessitura política da Lombardia de meados do século XVIII que consideramos mais relevantes para os propósitos da pesquisa e, a partir deles, tentaremos aprofundar a compreensão do significado mais geral do modelo jurídico-penal elaborado por Beccaria em Dei Delitti e delle Pene.

\section{$1 \quad$ Iluminismo e absolutismo: o reformismo habsbúrgico na Lombardia da metade do século XVIII}

O Iluminismo do século XVIII é apresentado geralmente como a filosofia que preparou a Revolução Francesa e a tomada do poder pela burguesia. De tal forma, teria um estreito vínculo com o Liberalismo e estaria, por princípio, oposto ao absolutismo monárquico. Não obstante a evidência dos vínculos entre a filosofia do Iluminismo e a Revolução Francesa e, portanto, entre o discurso iluminista e o discurso do liberalismo, este esquema está longe de constituir um modelo de interpretação válido universalmente. E se mesmo na França, onde o específico desenvolvimento econômico e institucional pôde colocar Liberalismo e Iluminismo lado a lado, as relações entre o absolutismo e o discurso iluminista apresentam sinuosidades ao longo do desenvolvimento de todo o processo, muito mais complexa é a relação da Filosofia das Luzes e de seus portadores com os monarcas absolutistas nos Estados 
onde o atraso econômico e institucional tornava anacrônica a recepção das idéias liberais ${ }^{2}$.

O discurso iluminista do século XVIII tem como marca principal a defesa da causa da emancipação humana pelo uso da razão. A fórmula célebre de Kant sapere aude (ousai saber), o apelo à autonomia do sujeito a partir das suas potencialidades racionais e o uso da ciência na dissolução da imagem mística e encantada do mundo são o que melhor caracteriza o pensamento das Luzes. No plano político, a reivindicação da emancipação pela razão fez com que o Iluminismo ganhasse uma tonalidade fortemente crítica que, em suas formas extremadas, assumiu um caráter contestatório consideravelmente subversivo em relação aos poderes constituídos. E quanto mais nos aproximamos dos grandes centros econômicos europeus, onde as pressões dos interessados em uma economia racional de mercado se confrontavam de forma cada vez mais irresolúvel com instituições burocráticas arcaicas, maiores eram os radicalismos conseqüentes do Iluminismo em seu combate contra o Antigo Regime. Ao contrário, onde o quadro político-social não se caracterizava por uma tensão tão acirrada colocada sobre estas bases, a pressão por mudanças institucionais pôde tomar o caminho de uma conciliação de interesses e se transformar em um moderado discurso reformista.

De outro lado, tal discurso reformista teve seus caminhos facilitados na medida em que a reforma institucional era, para os Estados economicamente periféricos da Europa da metade do século XVIII, como Prússia, Áustria e Portugal, uma necessidade impostergável. Assim, paralelo àquele discurso reformista de origem filosófica, houve uma tendência à racionalização instrumental das instituições administrativas que se guiava exclusivamente por considerações pragmáticas. Ambas as pressões por racionalização caminharam para uma confluência e o discurso filosófico reformador do Iluminismo se conciliou com as pretensões de monarcas absolutistas no sentido de uma centralização e modernização funcional no plano políticoinstitucional. Essa progressiva fusão dessas duas tendências que apontavam para a racionalização nos permite falar na formação de um absolutismo esclarecido nestes Estados europeus ${ }^{3}$.

\footnotetext{
${ }^{2}$ ASTUTI, Guido. O Absolutismo Esclarecido em Itália e o Estado de Polícia. Trad. António Manuel Hespanha. In: HESPANHA, António Manuel (org.). Poder e Instituições na Europa do Antigo Regime. Lisboa: Calouste Gulbenkian, 1984, p. 254. Na obra mencionada, Astuti analisa as relações entre Iluminismo e absolutismo no caso italiano, dentro do contexto do Estado de Polícia. Nessa obra ele percebe bem que a afinidade entre Iluminismo e liberalismo não é inflexível e deve necessariamente ser revista em determinadas circunstâncias. Achamos, entretanto, muito problemáticos alguns de seus posicionamentos.
}

${ }^{3}$ VALSECCHI, F. L'assolutismo illuminato in Europa. L'opera riformatrice di Maria Teresa e di Giuseppe II. Milano: Cooperativa Editoriale Universitaria Milanese, 1951-1952. 
Na França, o absolutismo monárquico encontra-se consolidado já na segunda metade do século XVII, em um processo iniciado com o governo de Richelieu e relativamente estabilizado com Luis XIV. Este absolutismo não implicava a eliminação completa do conjunto dos poderes intermediários da nobreza que inclusive constituiriam, no século seguinte, um dos pilares da teoria política de Montesquieu ${ }^{4}$. Mas o desenvolvimento econômico conseguido pela França com o comércio e com as manufaturas gerava os recursos necessários para que se sustentasse o exército e a estrutura administrativa da coroa e possibilitava que o Estado francês se estabelecesse como potência dentro do cenário político internacional, mesmo sem alcançar um grau maior de centralização administrativa. De tal forma, a eliminação destes poderes intermediários, embora fosse um desejo contínuo da coroa, não era, entretanto, uma necessidade tão proeminente. $O$ discurso iluminista francês não deixara de fazer críticas ao poder político da nobreza, mas a insensibilidade ou inaptidão da coroa francesa para atender a determinadas demandas e a existência de uma alta burguesia com poder político e social, somadas ao exemplo da Inglaterra, de onde vinha boa parte dos modelos filosóficos dos intelectuais franceses, fez com que o Iluminismo francês fosse perdendo a sua fé no absolutismo e começasse a caminhar em direção a valores liberais que preparariam a Revolução de $1789^{5}$.

Em Portugal, na Prússia e na Áustria, ao contrário, onde a situação econômica era muito mais incômoda, os monarcas sentiram a necessidade, em meados do século XVIII, de impor à sociedade a disciplina social necessária à promoção de uma política de potência, o que evidentemente implicava o incentivo e mesmo o impulso a atividades econômicas internas de onde se retirariam recursos para a organização da burocracia centralizada e do exército profissional permanente. $\mathrm{Na}$ Prússia, o absolutismo começa a chegar ao auge apenas entre os anos 30 e 40 do século XVIII, e na Áustria e em Portugal, apenas em meados da segunda metade do século XVIII, com certo atraso, portanto, em relação a França e, sobretudo nos últimos dois casos, em concomitância à recepção das idéias do Iluminismo. Esta circunstância parece ter imposto um significado diverso ao absolutismo e à sua relação com a Filosofia das Luzes.

A eliminação do conjunto dos poderes intermediários autônomos em favor da construção de meios administrativos que possibilitassem ao monarca a consecução das suas tarefas de reforma e modernização será desejada por ele e por todos os

\footnotetext{
${ }^{4}$ Vale ressaltar que os poderes intermediários do Antigo Regime não se resumem, evidentemente, aos poderes senhoriais nobiliárquicos. Sobre isso, ver: OESTREICH, G. Problemas Estruturais do Absolutismo Europeu. Trad. António Manuel Hespanha. In: HESPANHA, António Manuel (org.). Poder e Instituições na Europa do Antigo Regime. Lisboa: Calouste Gulbenkian, 1984, p. 187.

${ }^{5}$ ASTUTI, Guido. op. cit. pp. 260-1. Astuti enxerga bem a ausência de uma política reformadora na França e sua relação com a Revolução, mas falha, em nossa opinião, ao determinar suas causas.
} 
interessados no desenvolvimento das atividades econômicas ${ }^{6}$. Assim, a racionalização da administração pública e o bem-estar social produzido por este processo (identificado geralmente com a produção de bens materiais) permitirão ao discurso iluminista se conciliar com esta demanda que vem do trono, mas também de setores sociais politicamente inferiores do Antigo Regime. As esperanças de burgueses e setores intelectuais relativas à implementação de reformas acabam recaindo sobre a figura do príncipe e este, por sua vez, começa a perceber nesse apoio uma base importante para a consolidação e extensão de seu domínio no plano interno (dissolvendo os poderes intermediários que o obstaculizavam), bem como para o desenvolvimento de reformas destinadas a promover o fortalecimento institucional do Estado com relação a seus concorrentes externos. Neste contexto, o príncipe deve quase que necessariamente aparecer como o sujeito das reformas institucionais a quem incumbe reorganizar a sociedade de forma racional, orientando-a para a consecução do bem-estar dos súditos ${ }^{7}$. É precisamente assim que a literatura política começa a encará-lo. Nessa conciliação entre Iluminismo e absolutismo, os ideais liberais que tanta afinidade tinham com o discurso iluminista da autonomia individual fundada na racionalidade acabam por ficar em segundo plano.

É este conjunto de fenômenos que vemos desenhando-se na Lombardia no exato período em que Beccaria travava seus primeiros contatos com a literatura francesa que o levaria a escrever Dei Delitti e delle Pene. A tarefa de modernização institucional começou a ser executada pelo absolutismo austríaco depois da guerra de sucessão austríaca, já no reinado de Maria Teresa, graças ao impacto da questão da disputa pela Silésia ${ }^{8}$. A Lombardia, que era possessão da Áustria desde a guerra de sucessão espanhola, começaria a passar, a partir de então, por um programa de reformas. A primeira etapa do reformismo lombardo transcorreu entre 1749 e 1760 e foi levada a cabo, inicialmente, por Gian Luca Pallavicini e, depois, por Beltrame Cristiani e Pompeo Neri ${ }^{9}$. Essa etapa se encerraria, entretanto, no ano de 1757, com a partida de Neri para a Toscana. Com as atenções de Viena concentradas na Guerra dos Sete Anos (1756-63), o empenho reformador na

\footnotetext{
${ }^{6}$ FRIGO, Daniela. Principe, Giudici, Giustizia: Mutamenti Dottrinali e Vicende Istituzionali fra Sei e Settecento. In: COLAO, F.; BERLINGER, L. (orgs.). Iluminismo e Dottrine Penali. Milano: Giuffrè, 1990, p. 18.

${ }^{7}$ FRIGO, Daniela. op. cit., p. 20.

${ }^{8} \mathrm{~A}$ forma como os métodos administrativos do absolutismo prussiano foram construídos no âmbito da reflexão cameralística e, em especial, da ciência de polícia causaram profundas impressões no governo austríaco de Maria Teresa quando aplicados na Silésia, região que foi alvo de disputas entre Prússia e Áustria ao longo do século XVIII. Ver: SCHIERA, Pierangelo. Dall'arte di governo alle scienze dello Stato: Il cameralismo e l'assolutismo tedesco. Milano: Giuffrè, 1968, p. 228.

${ }^{9}$ WOOLF, Stuart J.; CARACCIOLO, Alberto; BADALONI, Nicola; VENTURI, Franco. Storia d'Italia. Vol. 3. Dal primo Settecento all'Unità. Torino: Einaudi, 1978, p. 85-6.
} 
Lombardia sofrerá uma interrupção. A segunda fase do reformismo lombardo começa em 1760, depois da chegada, no ano anterior, do conde Carlo di Firmian, novo plenipotenciário dos Habsburgs.

Quando, a partir de 1763, Carlo di Firmian e Kaunitz resolveram, por fim, acelerar o reformismo habsbúrgico na Lombardia, reanimando-o do abalo sofrido pela Guerra dos Sete Anos e pela contra-ofensiva patrícia e eclesiástica que marcou seu período de adormecimento, Milão já contava com um novo círculo de intelectuais que se candidatava ao protagonismo cultural dos próximos anos. Esse novo grupo de intelectuais reunia-se em torno de Pietro Verri e era composto por jovens, quase todos patrícios, dentre os quais podemos lembrar Alessandro Verri (irmão de Pietro), Alfonso Longo, Giambattista Biffi, Pietro Secco Comneno, Giuseppe Visconti, Sebastiano Franci, Luigi Lambertenghi e Paolo Frisi. É nesse grupo que se encontra também Cesare Beccaria. Sob a liderança de Pietro Verri, esses jovens formaram a chamada Società dei Pugni, associação destinada ao livre pensamento e à livre discussão, sem estatuto ou programa definido, e voltada a combater o atraso e o imobilismo da sociedade ${ }^{10}$. O novo grupo de jovens intelectuais inspirava-se entusiasticamente nas idéias do Iluminismo francês e assim, acompanhando o espírito dessa filosofia, reivindicava reformas que modernizassem a sociedade, que rompessem com as estruturas tradicionais que impediam o progresso e que reorganizassem, por fim, o conjunto social segundo os parâmetros da razão ${ }^{11}$.

Nos anos 60 do século XVIII temos na Lombardia austríaca, portanto, a insurgência de duas tendências reformadoras que buscavam a racionalização das instituições e da sociedade. A primeira partia da dinastia da Áustria, a casa de Habsburg, e era representada em Milão por Carlo di Firmian. O contexto de nascimento do reformismo austríaco, produto da inspiração do modelo prussiano baseado na Polizeiwissenschaft (Ciência da Polícia), permite ver claramente os objetivos que visava. A racionalização social e institucional deveria servir, sobretudo, ao fortalecimento do poder real, à consolidação do absolutismo e ao acúmulo de forças que garantissem uma posição vantajosa em relação aos conflitos externos. Por outro lado, na vizinha França, a década de 1750 tinha consolidado de uma vez por todas a nova Filosofia das Luzes. Podemos dizer, destarte, que ela marca definitivamente a ascensão dos philosophes na França. Teríamos, então, um novo grupo social cada vez mais influente, que acreditava poder reavaliar todas as crenças e condições da vida humana a partir da razão, removendo o que atrapalhava a realiza-

\footnotetext{
${ }^{10}$ CONSOLI, Domenico. Dall'arcadia all'illuminismo. Bologna: Cappelli, 1972, p. 126.

${ }^{11}$ WOOLF, Stuart J.; CARACCIOLO, Alberto; BADALONI, Nicola; VENTURI, Franco. op. cit., p. 86-7.
} 
ção das potencialidades humanas e promovendo o progresso. A força das idéias francesas garantiria sua difusão para toda a Europa e na década de 1760 elas já se faziam presentes em grande parte do continente. A instauração definitiva da Filosofia das Luzes na Lombardia, com o grupo de jovens filósofos da Società dei Pugni, traria consigo outra tendência que, ao lado da que partia da dinastia austríaca, apontaria para as reformas sociais e para a racionalização.

Desde o início, duas características marcam os escritos dos filósofos da Società dei Pugni: uma grande atenção dedicada às questões econômicas e uma aguerrida postura antinobiliárquica ${ }^{12}$. Ambas as questões articulam-se, conforme veremos, no problema maior do reformismo habsbúrgico em Milão. Em princípio, as idéias econômicas dos filósofos da Società dei Pugni favoreciam os setores produtores emergentes, como o dos proprietários de terras - que tentavam aproveitá-las utilizando métodos modernos voltados à produção para o mercado - e o dos empreendedores, que naquela mesma época já haviam instalado as primeiras manufaturas da Lombardia. Inspirando-se na literatura iluminista fisiocrática, que na década de 1760 já havia alcançado enorme popularidade, eles reivindicariam a eliminação dos vínculos feudais sobre a terra, os quais impediam seu uso econômico mais racional e eficiente, a eliminação das corporações que impediam a existência do livre-mercado, o aperfeiçoamento do sistema fiscal e administrativo em geral, e a eliminação da proibição de exercício do comércio para os nobres ${ }^{13}$. Como visto, a questão econômica era também importantíssima para a política de fortalecimento do poder real. A óbvia relação entre a situação financeira de um Estado e sua condição na política internacional faria com que a monarquia austríaca buscasse por todas as formas aumentar suas fontes de renda. A dinamização da economia, portanto, deveria necessariamente integrar a política de fortalecimento do poder monárquico, pois per-

\footnotetext{
${ }^{12}$ Antes do início da publicação de Il Caffè o grupo da Società dei Pugni já havia debutado no mundo das letras intervindo na questão da moeda de Milão. A intervenção se deu com Beccaria, através da seguinte obra: BECCARIA, Cesare. Del disordine e de' rimedi delle monete nello Stato di Milano. In: BECCARIA, Cesare. Opere. A cura di Sergio Romagnoli. Firenze: Sansoni, 1958. Na seqüência desenvolveu-se um acalorado debate, colocando a Società dei Pugni contra o marquês Carpani. CAPRA, Carlo. I progressi della ragione. Vita di Pietro Verri. Bologna: Il Mulino, 2002, p. 184-6. Depois das intervenções nessa discussão, os temas econômicos reapareceriam em inúmeras outras obras. Ver, a título de exemplo, as seguintes obras dos iluministas lombardos: BECCARIA, Cesare. Elementi di Economia Publica. In: BECCARIA, Cesare. Opere. A cura di Sergio Romagnoli. Firenze: Sansoni, 1958.; CARLI, Gianrinaldo. Del libero commercio de' grani. In: VENTURI, Franco. Illuministi Italiani. Tomo III. Riformatori Lombardi, Piemontesi e Toscani. Milano: Riccardo Riccardi; LONGO, Alfonso. Istituzioni Economico Politiche. In: VENTURI, Franco. Illuministi Italiani. Tomo III. Riformatori Lombardi, Piemontesi e Toscani. Milano: Riccardo Riccardi; VERRI, Pietro. Considerazioni sul commercio dello Stato di Milano. Milano: Bocconi, 1939.

${ }^{13}$ BECCARIA, Cesare. Elementi di Economia Publica... ; LONGO, Alfonso. Istituzioni economico...
} 
mitiria que se extraísse, pela tributação, os recursos necessários ao fortalecimento tanto da burocracia quanto do exército real. Essa dinamização econômica seria feita com o estímulo à produção e ao comércio interno, favorecendo deste modo justamente os setores produtores emergentes, sufocados pelas estruturas feudais e corporativas. Assim, as reformas executadas na Lombardia pela coroa austríaca estariam, em boa medida, de acordo com aquilo que era proposto pelo círculo dos intelectuais que escrevia no Il Caffè.

O tratamento da questão econômica por parte dos filósofos iluministas de Milão traz um novo componente ideológico para a característica luta dos monarcas contra os estamentos: agora eles não são apenas os rivais da coroa na luta pelo poder dentro do Estado; são também os que impedem a aplicação de uma política mais racional, voltada para o desenvolvimento econômico e para o conseqüente fortalecimento institucional, o que afeta também a luta política em face dos concorrentes externos. O poder político e os privilégios nobiliárquicos - especialmente patrícios - que caracterizavam a estrutura política milanesa eram óbices ao programa econômico modernizador e dinamizador que necessariamente deveria fazer parte do projeto absolutista da monarquia austríaca. Assim, o avanço do reformismo habsbúrgico na esfera econômica implicaria necessariamente o declínio do patriciado milanês ${ }^{14}$. Além do declínio do poder político patrício, as reformas econômicas ainda promoviam a ascensão de novos grupos sociais. Podemos dizer, assim, que a questão econômica não mudou apenas o sentido da luta interna pelo poder político entre o monarca e os estamentos, ela também alterou sua dinâmica, pois o papel negativo que a aristocracia acabaria adquirindo em relação ao desenvolvimento econômico (que, é claro, não interessava apenas à coroa, mas ao próprio conjunto social, de forma geral) contribuiria decisivamente para eliminar a hegemonia social da aristocracia. Além disso, o sucesso das reformas econômicas, ao promover a ascensão de novos grupos sociais, criaria uma enorme base social de apoio ao monarca ${ }^{15}$. Ante os benefícios sociais mais ou menos gerais advindos da política de fortalecimento econômico, a nobreza - e o patriciado em particular - cairá em progressivo e crescente descrédito em face do conjunto social ${ }^{16}$. A partir de então, dificilmente ela conseguirá mobilizar as massas, sejam urbanas ou camponesas, em rebeliões contra o poder real, tal como as que marcaram o século XVII em toda Europa.

\footnotetext{
${ }^{14}$ CARPANETTO, Dino; RICUPERATI, Giuseppe. L'Italia del Settecento: Crisi, Trasformazioni, Lumi. Roma-Bari: Laterza, 1994, p. 198.

${ }^{15}$ SCHOBER, Richard. Gli effetti delle riforme di Maria Teresa sulla Lombardia. In: MADDALENA, Aldo De; ROTELLI, Ettore; BARBARISI, Gennaro (orgs.). Economia, istituzioni, cultura in Lombardia nell'età di Maria Teresa. Volume II. Cultura e Società. Bologna: Il Mulino, 1982, p. 201-2.

${ }^{16}$ GORANI, Giuseppe. Il vero dispotismo. In: VENTURI, Franco. Illuministi Italiani. Tomo III. Riformatori Lombardi, Piemontesi e Toscani. Milano: Riccardo Riccardi.
} 
A percepção, por parte dos jovens filósofos, de que o monarca era a única força que, naquele contexto, realmente poderia realizar as reformas necessárias e implementar um processo de desenvolvimento econômico nos termos propostos levou-os definitivamente para o lado do absolutismo. A questão econômica ou, mais exatamente, a mesma posição em relação aos problemas econômicos propiciava a aproximação entre os filósofos do Il Caffè e o absolutismo austríaco. Na medida em que os estamentos, com seus privilégios, impediam o desenvolvimento econômico e a implementação de reformas de interesse geral, eles apareceriam nos escritos dos jovens iluministas lombardos como o verdadeiro poder despótico contra o qual se deveria lutar e contra o qual o soberano já estava efetivamente lutando ${ }^{17}$.

O absolutismo esclarecido é a fusão da tendência modernizadora e racionalizadora que vinha da filosofia iluminista com aquela outra tendência, também modernizadora e racionalizadora, que partia das dinastias reinantes em cada Estado. A articulação entre essas duas propostas reformadoras e a formação, a partir delas, de uma única tendência reformista que articulava os desígnios centralizadores dos monarcas, em sua luta pelo poder contra adversários internos e externos, com o anseio filosófico por reformas que melhorassem as condições de vida e promovessem o progresso humano implicava necessariamente a articulação entre os portadores dessa filosofia, os filósofos iluministas, e o projeto político absolutista em uma espécie de aliança, ainda que tácita. Para tornar isso possível, era necessário que os próprios sujeitos da filosofia iluminista aderissem ao projeto absolutista da casa da Áustria e que sua colaboração fosse aceita - isto é, que exercessem alguma influência sobre os caminhos trilhados pela coroa em sua luta pela centralização política e no que foi feito por ela com o poder concentrado em suas mãos ${ }^{18}$.

Como mencionado, os filósofos da Società dei Pugni contribuíram decisivamente, ao defender reformas que modernizassem a Lombardia, para reformular a imagem do monarca em sua empreitada absolutista. Mas para que a fusão da filosofia iluminista com a proposta absolutista realmente se realizasse - isto é, para que as duas tendências que buscavam, por motivos próprios, a racionalização institucional e social convergissem e formassem uma só tendência reformadora -, era necessário que os filósofos fossem incorporados, de alguma forma, ao projeto político

\footnotetext{
${ }^{17}$ GORANI, Giuseppe. Il vero dispotismo...; CAPPIELLO, Ida. L'idea di Stato nell'Illuminismo lombardo. In: MADDALENA, Aldo De; ROTELLI, Ettore; BARBARISI, Gennaro (orgs.). Economia, istituzioni, cultura in Lombardia nell'età di Maria Teresa. Volume II. Cultura e Società. Bologna: Il Mulino, 1982, p. 972-3.

${ }^{18}$ BARBARISI, Gennaro. L'elogio di Maria Teresa di Paolo Frisi. In: MADDALENA, Aldo De; ROTELLI, Ettore; BARBARISI, Gennaro (orgs.)s Economia, istituzioni, cultura in Lombardia nell'età di Maria Teresa. Volume II. Cultura e Società. Bologna: Il Mulino, 1982, p. 352.
} 
monárquico e passassem a exercer, com suas idéias, alguma influência importante. As características singularizadoras do contexto em que esse absolutismo tardio se desenvolvia determinavam suas necessidades, que, antes de qualquer coisa, diziam respeito ao aumento de eficiência da máquina burocrática e ao desenvolvimento econômico necessário para o fortalecimento institucional. Por um lado, isso demandava, de Viena, uma política reformadora que se dirigisse à modernização institucional e à racionalização burocrática das instituições; por outro, era necessário implementar políticas que rompessem com os entraves à dinamização da economia. Tudo isso determinaria o tipo de colaboração e de colaboradores demandados por Viena. Para que tal projeto fosse viável, era necessário, sobretudo, possuir um quadro administrativo que, além de fiel à coroa, fosse suficientemente competente para realizar as tarefas exigidas. A identificação entre a proposta absolutista e as reivindicações dos jovens filósofos do Il Caffè - baseadas sobretudo na questão econômica, isto é, na idêntica postura pró-desenvolvimentista, e na questão nobiliárquica, isto é, na postura antinobiliárquica e, principalmente, antipatrícia, além da notória capacidade intelectual daqueles jovens polemistas que, com seu jornal e suas obras individuais, opinavam sobre todas as questões importantes da política e da economia milanesas - não permitiria que fossem ignorados por muito tempo pelos representantes da coroa austríaca. A integração dos iluministas milaneses nos quadros funcionais da coroa, em sua empreitada absolutista, completa o processo de formação do absolutismo esclarecido na Lombardia austríaca ${ }^{19}$.

A fusão das duas tendências modernizadoras - a representada pela filosofia iluminista e a do absolutismo tardio - não era, entretanto, um encontro perfeito. As urgentes necessidades que atingiam com toda força o projeto de poder daquelas dinastias que se confrontavam, de tempos em tempos, no cenário político internacional e que, em meio a uma economia capitalista cada vez mais desenvolvida, miravam-se no exemplo de potências como a França e a Inglaterra, obrigavam-nas a um agressivo programa de racionalização social que deveria tornar mais eficiente a administração do Estado, fomentar o desenvolvimento econômico e submeter os estamentos e os poderes políticos autônomos. O Iluminismo, por outro lado, era uma corrente filosófica que fundava na racionalidade humana um projeto de emancipação. Emancipação da tradição, dos dogmas religiosos, das forças da natureza, mas uma emancipação também do poder político ilegítimo, assim considerado aquele que não se fundava na autonomia humana individual, inerente à idéia de que cada homem é um ser racional. A poderosa influência do liberal John Locke na formação do ideário iluminista, tão perceptível quando se vasculham os textos da filosofia francesa do século XVIII, deixou marcas profundas. Portanto, se bem analisarmos,

${ }^{19}$ CAPPIELLO, Ida. L'idea di stato..., p. 969. 
apesar da convergência verificada entre os dois, verificamos que Iluminismo e absolutismo possuíam interesses específicos, se considerados um em relação ao outro. Não havendo, assim, uma coalizão perfeita nesse compromisso entre o absolutismo e a filosofia iluminista, o lugar central, o lugar de comando caberia certamente ao absolutismo. A racionalidade das Luzes ficava, de certa forma, subordinada à racionalidade do acúmulo de poder - e é claro que algo do espírito original do Iluminismo deveria perder-se.

A filosofia do século XX ensina que o projeto da modernidade, do qual o Iluminismo é o principal representante, ancorava-se em uma racionalidade instrumental, que apontava para a dominação, e em uma racionalidade comunicativa, que apontava para a emancipação - ou em um pilar regulatório e em outro emancipatório, se se preferir ${ }^{20}$. Quando olhamos para as idéias que fervilhavam nas obras dos autores do século XVIII, vemos que as duas coisas, dominação e emancipação, estavam profundamente imbricadas. Segundo a crítica filosófica contemporânea, os problemas da modernidade teriam começado quando o aspecto instrumental colonizou o comunicativo-emancipatório. $\mathrm{O}$ fato de os ideais democráticos e republicanos do Iluminismo terem sido relegados a segundo plano, na sua fusão com o absolutismo, talvez seja um indício de que efetivamente, na aliança da Filosofia das Luzes com aquelas formas políticas autocráticas, aquele elemento instrumental de sua racionalidade tenha sido isolado e alçado ao primeiro plano.

A absorção dos intelectuais do iluminismo lombardo no projeto político do absolutismo habsbúrgico, na condição de funcionários da coroa, colocou a capacidade intelectual daqueles jovens intelectuais a serviço do planejamento das estratégias da ascensão da autocracia régia contra a pluralidade de poderes políticos que caracterizava a sociedade do Antigo Regime. Nesse processo, o intelectual iluminista, assim absorvido e transformado em funcionário administrativo da coroa, tem seu papel redefinido: agora ele não é mais o conselheiro do rei que pensa globalmente a sociedade, não apenas ajudando o monarca a alcançar as metas estipuladas mas interferindo também na definição das próprias metas; agora ele é o técnico em problemas jurídicos, econômicos ou cameralísticos, que articula os meios necessários para alcançar os fins determinados pelo rei e seus altos ministros ${ }^{21}$. É claro que aquela imagem de conselheiro do rei, ao menos na Lombardia, nunca correspondeu

\footnotetext{
${ }^{20}$ Nos referimos aqui, evidentemente, às idéias de Jürgen Habermas e Boaventura de Sousa Santos, respectivamente.

${ }^{21}$ As Consulte Amministrative, de Beccaria, são um eloqüente exemplo do tipo de trabalho intelectual que se esperava de um funcionário josefino (BECCARIA, Cesare. Consulte Amministrative. In: BECCARIA, Cesare. Opere. A cura di Sergio Romagnoli. Firenze: Sansoni, 1958). Sobre esse tema, ver: CAPRA, Carlo. Il gruppo del "Caffè" e le riforme. In: FERRONE, Vincenzo; FRANCIONI, Gianni (orgs.). Cesare Beccaria: la pratica dei lumi. Atti del Convegno. Firenze: Olschki, 2000, p. 66.
} 
propriamente à realidade, mas era a maneira como os iluministas lombardos compreendiam, em princípio, seu papel dentro do projeto modernizador e reformador do absolutismo habsbúrgico. A subordinação do intelectual iluminista ao projeto autocrático do absolutismo tardio é a subordinação do próprio Iluminismo aos desígnios da pura acumulação do poder, à lógica de uma espécie de nova razão de Estado ${ }^{22}$. Pode-se perguntar, certamente, se isso ainda tem alguma coisa a ver com Iluminismo ou se estamos em uma zona na qual o que se vê é apenas a projeção das sombras criadas por suas Luzes. Esse talvez seja, entretanto, um falso problema, pois de qualquer maneira a sombra sempre tem alguma coisa a ver com a luz que a torna possível. Cesare Beccaria talvez tenha representado jutamente o caso mais extremo de tal fenômeno ${ }^{23}$.

A história do Iluminismo lombardo guarda, entretanto, um momento de singular brilhantismo para a cultura italiana do século XVIII - um momento em que, em Paris, capital mundial da Filosofia das Luzes, falava-se com curiosidade e entusiasmo dos progressos da École di Milan. O ponto-chave desse momento, seu fato propulsor, foi a publicação da obra Dei Delitti e delle Pene, de Cesare Beccaria. Graças a essa obra, a cosmopolita república das letras da Europa tomou conhecimento da existência dos jovens patrícios milaneses. A partir de então, Beccaria seria, perante a Europa, a figura central do Iluminismo na Lombardia, o grande representante das Luzes em Milão - o que lhe renderia uma enorme inveja e um profundo rancor da parte de Pietro Verri. Veremos então Beccaria trocar correspondência com alguns ilustres nomes da Ilustração francesa, ser recebido em Paris como celebridade pelo círculo dos philosophes e ser convidado por Catarina II, soberana da Rússia, para escrever o código penal de seu império. Veremos também Voltaire, o arrogante líder do partido dos philosophes franceses, bajulado por uma infinidade de jovens escritores que acorriam a Paris buscando fazer carreira no mundo intelectual, pedir humildemente a Beccaria alguns conselhos jurídicos referentes aos célebres processos em que se envolveu nas décadas de 1760 e $1770^{24}$.

Nesse momento de brilhantismo do Iluminismo lombardo, protagonizado justamente por Beccaria, aquele que mais do que qualquer outro simbolizaria seu declínio, não haveria nada que pudesse indicar os destinos da cultura iluminista em Milão? Não haveria nada que antecipasse a triste decadência dos valores liberais, republicanos e democráticos, tão profundamente ligados ao código genético do Iluminismo,

\footnotetext{
${ }^{22}$ FRIGO, Daniela. op. cit.

${ }^{23}$ CAPRA, Carlo. Il gruppo..., p. 68; ZORZI, Renzo. Cesare Beccaria. Il Drama della Giustizia. Milano: Borighieri, 1996.

${ }^{24}$ Veja-se, a esse respeito, a carta de Voltaire a Beccaria contida em: VOLTAIRE. Comentários Políticos. Trad. Antonio de Pádua Danesi. Rev. da trad. Cláudia Berliner. São Paulo: Martins Fontes, 2001.
} 
e a ascensão exclusivista de uma racionalidade instrumental soberana e autocrática? São precisamente essas as perguntas que tentaremos responder, analisando alguns aspectos da obra Dei Delitti e delle Pene.

\section{Um projeto de Direito Penal para o absolutismo esclarecido: o utilitarismo em Dei Delitti e delle Pene}

Quando se abre Dei Delitti e delle Pene não se pode deixar de notar a presença de idéias contratualistas como fundamento da ordem política em que Beccaria insere seu modelo de direito penal ${ }^{25}$. Muito já se discutiu sobre a relação deste contratualismo jusnaturalista com as idéias de natureza utilitarista que também vemos perpassar o texto ${ }^{26}$. Ao contrário, entretanto, do que se poderia imaginar, as duas teorias que entrarão para os anuários da história do pensamento político como mutuamente excludentes chegavam para Beccaria de uma única e mesma fonte: a obra do filósofo francês Claude-Adrien Helvétius ${ }^{27}$. Todo o conjunto da reflexão política de Beccaria fundamenta-se na influência exercida sobre ele pela obra $D o$ Espírito, de Helvétius ${ }^{28}$, onde o cálculo de utilidades que, no contratualismo do modelo hobbesiano-lockeano, leva os indivíduos à passagem do estado de natureza para o estado social sofre um aprofundamento psicológico até levar à formação de um novo modelo de abordagem política em que o próprio raciocínio contratualista acabaria sendo supérfluo e em que surgiria uma nova forma de se trabalhar com o cálculo de utilidades ${ }^{29}$.

Quando falamos em utilitarismo ou raciocínio utilitarista nos referimos ao cálculo de utilidade, ao cálculo do útil. No contratualismo inglês, os sujeitos realizam a

\footnotetext{
${ }^{25}$ BECCARIA, Cesare. Dei Delitti e delle Pene, 1987, pp. 10-2.

${ }^{26}$ Uma das mais notórias é esta, em que Beccaria profere a máxima utilitarista quase com as mesma palavras que usará Bentham tempos depois: "Apriamo le istorie e vedremo che le leggi, che pur sono o dovrebbon esser patti di uomini liberi, non sono state per lo più che lo stromento delle passioni di alcuni pochi, o nate da una fortuita e passeggiera necessità; non giá dettate da un freddo esaminatore della natura umana, che in un sol punto concentrasse le azioni di una moltitudine di uomini, e le considerasse in questo punto di vista: la massima felicità divisa nel maggior numero" (BECCARIA, Cesare. Dei Delitti e delle Pene. Milano: Garzanti, 1987, p. 8).

${ }^{27} \mathrm{O}$ enorme desconhecimento da obra de Helvétius levou inúmeros autores a falar de um Beccaria roussouniano, lockeano etc. As relações entre contratualismo e utilitarismo nas obras de Beccaria e de Helvétius são muito bem analisadas na obra: FRANCIONI, Gianni.

Beccaria filosofo utilitarista. In: Cesare Beccaria tra Milano e l'Europa: convegno di studi per il $250^{\circ}$ anniversario della nascita. Milano: Cariplo-Laterza, 1990.

${ }^{28}$ BECCARIA, Cesare. Carta de Beccaria...,1996, p. 159.

${ }^{29}$ FRANCIONI, Gianni. Beccaria filosofo utilitarista...; HELVETIUS, Claude-Adrien. Del Espiritu. Trad. José Manuel Bermudo. Madrid: Nacional, 1984.
} 
passagem para o estado social em função dos inconvenientes dos estado de natureza. Os objetivos visados pelos sujeitos, desde logo objetivos egoísticos e individualistas (seja a proteção da vida, seja a proteção da propriedade), são o que os leva, através de um raciocínio pragmático de meios e fins, a realizar a passagem para o estado social. A base do raciocínio é a pressuposição da racionalidade individual ou da condição natural do homem como ser racional - por isso pode-se falar em direito natural ou racional. Entretanto, no modelo do contratualismo inglês o sujeito busca a gratificação hedonista, mas age calculando as conseqüências, de forma a interferir sobre as próprias condições políticas e sociais de suas ações. Em outras palavras, nesse esquema de pensamento a estruturação da arquitetura político-social é feita pelos próprios sujeitos sociais, em um hipotético acordo, através do cálculo de utilidade pelo qual, partindo-se do pressuposto de que todos os outros sujeitos são igualmente racionais, cada sujeito planeja a estrutura social que corresponde melhor a seus interesses individuais. A reconstrução hipotética que visa sobretudo por à mostra a lógica que orienta a dinâmica social tem como objetivo fornecer um critério para se distinguir o poder legítimo do ilegítimo. Evidentemente, a condição natural do homem não é semelhante à condição natural de qualquer outro ser da natureza, pois a natureza do ser humano é precisamente a racionalidade: o homem é um ser racional. Essa é, para os teóricos do contratualismo, a essência imutável do ser humano, aquilo que o torna propriamente humano.

No utilitarismo, entretanto, há uma espécie de bifurcação do cálculo da utilidade. Se no contratualismo ele era a base para que o sujeito planejasse a ação segundo seus interesses individuais de forma a, ao mesmo tempo, planejar a própria estrutura político-social em que se inserirá ${ }^{30}$, no utilitarismo, ao contrário, as coisas se separam. Os sujeitos sociais permanecem guiando a vida hedonisticamente a partir do cálculo de utilidades, isto é, planejando suas ações segundo seus objetivos egoísticos. A função, porém, de planejar globalmente a sociedade segundo o bemcomum - que por sua vez também é determinado a partir de critérios hedonísticoutilitarísticos e, portanto, pelo cálculo de utilidades - passa a um terceiro: o Legislador. No modelo do utilitarismo, o ser humano é interpretado como uma máquina que funciona segundo a necessidade de obter prazer e de fugir da dor, e que, portanto, guia suas ações realizando uma espécie de cálculo do prazer ou da dor que cada uma das ações possíveis lhe trará. De tal forma, surge a idéia de que, manipulando os objetos que afetam a sensibilidade humana, pode-se direcionar a ação dos seres humanos da maneira que se desejar. Torna-se possível planejar, assim, com o domí-

\footnotetext{
${ }^{30}$ Em outras palavras, a ação que brota do cálculo de utilidades do contrato social é a ação que estrutura a própria sociedade, a ação que celebra o pacto social (com cada uma de suas cláusulas racionalmente escolhidas) onde é definida a estrutura social.
} 
nio dos princípios utilitaristas que governam a ação humana, o funcionamento da sociedade. O cálculo de utilidades permite determinar, por conseqüência, os caminhos para se chegar ao "bem-comum", considerado assim o máximo de felicidade (enquanto prazer sensível) distribuída entre o maior número de pessoas. O Legislador poderá, portanto, planejar a arquitetura social de forma a que o prazer ou o interesse individual esteja sempre conectado com o interesse do conjunto social -o que significa direcionar as ações individuais, manobrando a sensibilidade humana, para o interesse geral.

Assim, no modelo político do utilitarismo, o cálculo de utilidades é feito em duas etapas: na primeira, o Legislador determina o interesse geral e planeja a arquitetura político-social; na segunda, os sujeitos-agentes, buscando o máximo de gratificação individual, executam, ainda que sem saber, o planejamento social, e realizam, buscando exclusivamente seu interesse pessoal, o interesse comum, o bem geral. Podemos dizer, portanto, que o cálculo de utilidades, no nível do planejamento social, passa para o Legislador, mas que os cidadãos, em sua ação reflexa, continuam calculando as utilidades para escolher quais ações realizar. Por fim, devemos lembrar que esse cálculo que os sujeitos-agentes realizam para decidir sobre suas ações não é necessariamente consciente. $\mathrm{Na}$ verdade, ele pode assumir muitas vezes a forma de um reflexo condicionado, sendo realizado inconscientemente. Os motivos aduzidos por Beccaria para sustentar a necessidade da presteza das penas deixam isso muito claro: ela deve suceder o mais rápido possível ao delito para que, na mente dos "celerados", a idéia do crime seja acompanhada necessariamente da idéia do desprazer da pena ${ }^{31}$. É assim que, na passagem do contratualismo para o utilitarismo, a ênfase migra da racionalidade para a passionalidade dos sujeitosagentes ou, se se preferir, da calculabilidade racional-consciente para o condicionamento passional-inconsciente.

Esse desmembramento do cálculo de utilidades e o deslocamento de seu nível social-organizativo para a alçada do Legislador possuem uma enorme afinidade com a redefinição do papel do monarca no contexto do desenvolvimento do absolutismo político. De fato, há uma marcante e inegável proximidade entre o Legislador, do qual falam explicitamente Helvétius e Beccaria, e a imagem do rei-legislador da reflexão pró-absolutista, que organiza a sociedade através da legislação. Além dis-

\footnotetext{
31 "Ho detto che la prontezza delle pene è più utile, perché quanto è minore la distanza del tempo che passa tral la pena ed il misfatto, tanto è più forte e più durevole nell'animo umano l'associazione di queste due idee, delitto e pena, talché insensibilmente si considerano uno come cagione e l'altra come affetto necessario immancabile. Egli è dimostrato che l'unione delle idee è il cemento che forma tutta la fabbrica dell'intelletto umano, senza di cui il piacere ed il dolore sarebbero sentimenti isolati e di nessun effetto" (BECCARIA, Cesare. Dei Delitti..., p. 46).
} 
so, as necessidades econômicas em meio às quais se desenvolveu o absolutismo tardio do século XVIII acabaram levando ao surgimento de uma espécie de utilitarismo político-econômico dentro da reflexão pró-absolutista, como a que encontramos na Ciência da Polícia. A necessidade de aumentar o volume das atividades econômicas internas para incrementar a arrecadação encontrava-se com a vontade dos setores ascendentes, nomeadamente a burguesia, de desenvolver atividades econômicas. Destarte, a defesa do absolutismo acabava acompanhada da idéia de que a tarefa do soberano (absoluto) era promover o bem-estar comum, que por sua vez era identificado com o aumento de bens materiais da sociedade. Esse utilitarismo político-econômico que compõe a reflexão pró-absolutista cria outra frente de afinidade entre o absolutismo monárquico e o utilitarismo filosófico que surge dentro do Iluminismo. O monarca absoluto que concentra em si o poder político para usá-lo na racionalização social e no fomento ao desenvolvimento econômico interno poderia ser progressivamente identificado com o Legislador que organiza a sociedade segundo os princípios da moral utilitarista para promover seu aperfeiçoamento geral.

Quando analisamos detidamente Dei Delitti e delle Pene, observamos que no cômputo geral a argumentação contratualista ocupa uma pequena parte. Ela aparece no começo do texto, onde o autor disserta sobre os fundamentos da ordem política e do direito penal, sobre o fundamento da atividade legislativa, sobre a separação entre os poderes de fazer e de aplicar as leis, e sobre a questão da interpretação ${ }^{32}$. Posteriormente, quando Beccaria trata da questão da pena de morte, os argumentos utilitaristas que buscam provar sua inutilidade são combinados com reflexões contratualistas que buscam demonstrar sua ilegitimidade ${ }^{33}$. Assim, podemos dizer que, na reflexão de Beccaria, a idéia de contrato social funciona apenas como fundamento legitimador das instituições políticas e jurídicas. O bom governo e a boa política legislativa, entretanto, fundam-se nas teorias utilitaristas que ofereceriam um conhecimento dos princípios que orientam a ação humana ou, em outras palavras, no conhecimento da psicologia humana.

Sobre isso algumas considerações merecem ser feitas. O utilitarismo possui, enquanto teoria política, esse caráter de ciência do bom governo, onde assume a forma de uma teoria destinada a ensinar como dirigir a sociedade. Todavia, tal aspecto sofre uma espécie de aprofundamento ou adensamento no contexto político do absolutismo tardio. A necessidade de maximizar o controle do soberano sobre a sociedade para viabilizar o próprio projeto político absolutista faz parte das condições em que o absolutismo tardio se desenvolveu. Para que países como Prússia,

\footnotetext{
32 BECCARIA, Cesare. Dei Delitti..., 1987, pp. 10-4.

${ }^{33}$ Idem, p. 59.
} 
Áustria e Portugal vencessem o atraso em que se encontravam em relação às principais potências européias de então - a Inglaterra e, sobretudo, a França - era necessário que o poder político central desenvolvesse técnicas que lhe permitissem impor, a partir de cima, a modernização econômica ${ }^{34}$.

No campo jurídico, isso se coloca como o problema da eficácia da norma jurídica da coroa, ou seja, da capacidade de a norma jurídica se fazer cumprir. Esse pode ser considerado um dos problemas centrais do livro de Beccaria, visível sobretudo na questão da mitigação das penas e da graça. A brutalidade das penas do direito penal do Antigo Regime era um dos componentes essenciais de sua escandalosa ineficácia; o objetivo da pena era fundamentalmente simbólico: buscava-se aterrorizar. A graça real, por meio da qual se afastava a aplicação da pena, era seu complemento necessário. Por meio dela, o soberano se legitimava perante o organismo social e, principalmente, perante o beneficiado. Todo o modo de operar do direito fundava-se, assim, no arbítrio e a renúncia à eficácia do direito penal, implícita nessa estrutura, tolhia a capacidade real de, por meio dele, interferir sobre o conjunto da sociedade. Isso, aos olhos iluministas, era profundamente irracional. Portanto, para Beccaria, a mitigação das penas ${ }^{35}$, a par de suas razões humanitárias (que certamente existiam), era o pressuposto para que a graça fosse eliminada do direito penal e para que ele, conseqüentemente, ganhasse a eficácia necessária para maximizar o poder de controle do soberano sobre a sociedade ${ }^{36}$. O sistema jurídico-penal proposto por Beccaria encaixa-se perfeitamente, assim, na dinâmica política do absolutismo tardio, onde o que importa é dar ao soberano os meios para direcionar a sociedade, intervir nela e controlá-la.

A teoria das penas de Beccaria repete em muitos pontos o que escrevera Montesquieu. Em $O$ Espírito das Leis, ele havia iniciado uma racionalização da repressão penal, estabelecendo o princípio da legalidade, elegendo a prevenção do crime como a principal meta do direito penal, defendendo a mitigação das penas (sob o argumento de que não é sua severidade que desvia os homens da prática dos crimes, mas a certeza da punição), condenando a tortura e defendendo a necessida-

\footnotetext{
${ }^{34}$ SCHIERA, Pierangelo. Dall'arte di governo...; ASTUTI, Guido. O Absolutismo Esclarecido em Itália...

35 "La certezza di un castigo, benché moderato, farà sempre una maggiore impressione che non il timore di un altro piú terribile, unito colla speranza dell'impunità" (BECCARIA, Cesare. Dei Delitti..., 57).

36 "A misura che le pene divengono più dolci, la clemenza ed il perdono diventano meno necessari. Felice la nazione nella quale sarebbero funesti! La clemenza dunque, quella virtù che è stata talvolta per un sovrano il supplemento di tutt'i doveri del trono, dovrebbe essere esclusa in una perfetta legislazione dove le pene fossero dolci ed il metodo di giudicare regolate e spedito" (BECCARIA, Cesare. Dei Delitti..., p. 96).
} 
de de uma relação de proporcionalidade entre as penas e os delitos ${ }^{37}$. Tudo isso, como sabem os leitores de Beccaria, está presente em Dei Delitti e delle Pene. Entretanto, essa teoria das penas recolhida de Montesquieu seria aprofundada com as teorias helvetianas. Com o contributo helvetiano, o processo de racionalização do sistema penal conduzido por Beccaria visava não apenas fazer com que a pena cumprisse melhor a finalidade de prevenção do crime, mas também com que o direito penal contribuísse para que os interesses individuais conduzissem ao chamado interesse comum, que por sua vez era determinado pelo Legislador (e, por que não dizer, pelo rei-legislador). A aplicação, ao estudo do direito penal, do utilitarismo aprendido com Helvétius objetivava fornecer um fundamento sólido para seu uso enquanto instrumento para se modelar a sociedade.

Chegamos, então, ao tema do uso instrumental do direito. $\mathrm{O}$ aspecto jurídico do desenvolvimento do absolutismo dentro da modernidade era a aniquilação daquele particularismo ${ }^{38}$ que marcava a estrutura jurídica do Antigo Regime. Esse particularismo jurídico fundava-se na pluralidade de fontes de direito concorrentes e em seu complemento, a pluralidade de jurisdições (usamos a expressão em seu sentido moderno). A afirmação do poder político monárquico foi completada, no campo jurídico, pela afirmação da legislação real sobre todas as outras fontes jurídicas. A supremacia da legislação real sobre o direito romano, o direito consuetudinário, o direito corporativo, tinha, obviamente, o objetivo de permitir à coroa a concretização, pelo direito, de suas intenções. No contexto do absolutismo tardio, sob a influência da reflexão cameralística - em especial da Ciência de Polícia - e das teses iluministas que outorgavam ao ser humano a capacidade de, pelo uso da razão, subjugar a realidade que o circunda e colocá-la a seu serviço, esse uso instrumental do direito tende a ganhar em sistematicidade e a conectar-se com sistemas de planejamento social. $\mathrm{O}$ uso das teorias utilitaristas dentro desses projetos de organização social a ser realizados com o instrumental fornecido pelo direito é, assim, um dos pontos altos do projeto jurídico ${ }^{39}$ da modernidade.

\section{Conclusão}

O Iluminismo milanês do Circulo do Caffè desenvolveu-se num contexto em que as tendências modernizadoras que partiam da sociedade civil eram sufocadas

\footnotetext{
${ }^{37}$ TARELLO, Giovanni. Montesquieu Criminalista. In: TARELLO, Giovanni (org.). Materiali per una Storia della Cultura Giuridica. Vol. V. Genova: Il Mulino, 1975, p. 15.

${ }^{38}$ Idem. Storia della...

${ }^{39}$ A construção jurídica da modernidade, no liberalismo clássico, foi analisada por Pietro Costa na seguinte obra: COSTA, Pietro. Il Progetto Giuridico. Ricerche sulla giurisprudenza del liberalismo classico. Milano: Giuffrè, 1976.
} 
pelas estruturas do poder patrício. A Lombardia daqueles anos, ao contrário, era palco de um potente programa reformista e modernizador levado a cabo dentro do projeto autocrático do absolutismo habsbúrgico. Em tal contexto, a identificação dos jovens intelectuais com a causa da modernização absolutista foi praticamente inevitável. Os intelectuais iluministas da Società dei Pugni são, destarte, absorvidos por esse processo de modernização conservadora e passam a integrar os quadros funcionais submetidos à coroa austríaca e a seus representantes lombardos. Algumas conseqüências, desde logo, são importantes. A primeira é uma espécie de abertura de horizontes sofrida pela proposta absolutista, em função da influência desses intelectuais, essencial para a formação do fenômeno do absolutismo esclarecido. A segunda é que a orientação política do Iluminismo lombardo, na medida em que ele se vinculava a um projeto de modernização institucional conduzido no seio do absolutismo, acaba sendo desviada de tendências políticas mais radicais, deixando progressivamente de lado as idéias republicanas que provinham de suas influências francesas e possuíam certa afinidade com o espírito original da Filosofia das Luzes.

Cesare Beccaria escreveu Dei Delitti e delle Pene no contexto de fusão entre as tendências reformistas da dinastia habsbúrgica em Milão. Assim, a adesão dos filósofos iluministas ao projeto modernizador da coroa austríaca não poderia deixar de aparecer em sua obra. O projeto político do absolutismo no século XVIII incorporava necessariamente, em face das circunstâncias em que teria de se desenvolver, um programa de modernização econômica que propiciasse a criação dos recursos para o fortalecimento régio. As propostas de Beccaria, a par de suas tendências humanitárias, visavam também dar maior eficiência ao sistema penal. $\mathrm{O}$ dirigismo social da teoria utilitarista conciliava-se com a imagem do rei-legislador que se construía na literatura pró-absolutista. Assim o uso do utilitarismo helvetiano por parte de Beccaria, na construção de seu modelo de sistema penal, tinha como objetivo justamente aproveitar as contribuições que ele poderia dar para construir métodos eficazes de intervenção social que possibilitassem ao monarca direcionar a sociedade. Portanto, o papel exercido pela teoria utilitarista - voltada sobretudo a fornecer ao soberano os métodos indicados para a subordinação da sociedade civil, mais ou menos como fazia a Ciência de Polícia e a cameralística - e o implícito desapreço pela autonomia do sujeito que ela implica, dão mostras de que, ao lado dos motivos humanistas que inspiraram Beccaria, questões de outra ordem estavam em debate. 


\section{Referências}

ASTUTI, Guido. O Absolutismo Esclarecido em Itália e o Estado de Polícia. Trad. António Manuel Hespanha. In: HESPANHA, António Manuel (org.). Poder e Instituições na Europa do Antigo Regime. Lisboa: Calouste Gulbenkian, 1984.

BARBARISI, Gennaro. L'elogio di Maria Teresa di Paolo Frisi. In:

MADDALENA, Aldo De; ROTELLI, Ettore; BARBARISI, Gennaro (orgs.). Economia, istituzioni, cultura in Lombardia nell'età di Maria Teresa. Volume II: Cultura e Società. Bologna: Il Mulino, 1982.

BECCARIA, Cesare. Carta de Beccaria a Morellet. Dos Delitos e das Penas. 11. ed. Trad. Torrieri Guimarães. São Paulo: Hemus, 1996.

. Consulte Amministrative. In: BECCARIA, Cesare. Opere. A cura di Sergio Romagnoli. Firenze: Sansoni, 1958.

. Dei Delitti e delle Pene. Milano: Garzanti, 1987.

. Del disordine e de' rimedi delle monete nello Stato di Milano. In: BECCARIA, Cesare. Opere. A cura di Sergio Romagnoli. Firenze: Sansoni, 1958.

. Elementi di Economia Publica. In: BECCARIA, Cesare. Opere. A cura di Sergio Romagnoli. Firenze: Sansoni, 1958.

BIAGINI, Enza. Introduzione a Beccaria. Roma-Bari: Laterza, 1992. CAMPA, Riccardo. Prefácio in Dos Delitos e das Penas. Trad. Lucia Guidicini e Alessandro Berti Contessa. São Paulo: Martins Fontes, 1997. CAPPIELLO, Ida. L'idea di Stato nell'Illuminismo lombardo. In: MADDALENA, Aldo De; ROTELLI, Ettore; BARBARISI, Gennaro (orgs.). Economia, istituzioni, cultura in Lombardia nell'età di Maria Teresa. Volume II: Cultura e Società. Bologna: Il Mulino, 1982.

CAPRA, Carlo. Il gruppo del "Caffè" e le riforme. In: FERRONE, Vincenzo; FRANCIONI, Gianni (orgs.). Cesare Beccaria: la pratica dei lumi. Atti del Convegno. Firenze: Olschki, 2000. 2002.

. I progressi della ragione. Vita di Pietro Verri. Bologna: Il Mulino,

CARLI, Gianrinaldo. Del libero commercio de' grani. In: VENTURI, Franco. Illuministi Italiani. Tomo III. Riformatori Lombardi, Piemontesi e Toscani. Milano: Riccardo Riccardi.

CARPANETTO, Dino; RICUPERATI, Giuseppe. L'Italia del Settecento: crisi, trasformazioni, lumi. Roma-Bari: Laterza, 1994. 
CONSOLI, Domenico. Dall'arcadia all'illuminismo. Bologna: Cappelli, 1972. COSTA, Pietro. Il Progetto Giuridico. Ricerche sulla giurisprudenza del liberalismo classico. Milano: Giuffrè, 1976.

FRANCIONI, Gianni. Beccaria filosofo utilitarista. In: Cesare Beccaria tra Milano e l'Europa: convegno di studi per il $250^{\circ}$ anniversario della nascita. Milano: Cariplo-Laterza, 1990.

FRIGO, Daniela. Principe, Giudici, Giustizia: Mutamenti Dottrinali e Vicende Istituzionali fra Sei e Settecento. In: COLAO, F.; BERLINGER, L. (orgs.). Iluminismo e Dottrine Penali. Milano: Giuffrè, 1990.

GASPARI, Gianmarco. Beccaria e la crisi del sensismo. In: Cesare Beccaria tra Milano e l'Europa: convegno di studi per il $250^{\circ}$ anniversario della nascita. Milano: Cariplo-Laterza, 1990.

GORANI, Giuseppe. Il vero dispotismo. In: VENTURI, Franco. Illuministi Italiani. Tomo III. Riformatori Lombardi, Piemontesi e Toscani. Milano: Riccardo Riccardi.

HELVÉTIUS, Claude-Adrien. Carta a Montesquieu. In: CONDILLAC, Étienne Bonnot de; HELVÉTIUS, Claude-Adrien; DEGÉRANDO, Joseph-Marie. Textos Escolhidos. Trad. Luiz Roberto Monzani et al. 2. ed. São Paulo: Abril Cultural, 1979.

. Del espiritu. Trad. José Manuel Bermudo. Madrid: Nacional, 1984.

HESPANHA, António Manuel. Para uma teoria da história institucional do Antigo Regime. In: HESPANHA, António Manuel (org.). Poder e instituições na Europa do Antigo Regime. Lisboa: Calouste Gulbenkian, 1984.

LONGO, Alfonso. Istituzioni economico politiche. In: VENTURI, Franco. Illuministi Italiani. Tomo III. Riformatori Lombardi, Piemontesi e Toscani. Milano: Riccardo Riccardi;

OESTREICH, G. Problemas Estruturais do Absolutismo Europeu. Trad. António Manuel Hespanha. In: HESPANHA, António Manuel (org.). Poder e Instituições na Europa do Antigo Regime. Lisboa: Calouste Gulbenkian, 1984.

SCHIERA, Pierangelo. Dall'arte di governo alle scienze dello Stato: Il cameralismo e l'assolutismo tedesco. Milano: Giuffrè, 1968.

SCHOBER, Richard. Gli effetti delle riforme di Maria Teresa sulla Lombardia. In: MADDALENA, Aldo De; ROTELLI, Ettore; BARBARISI, Gennaro (orgs.) Economia, istituzioni, cultura in Lombardia nell'età di Maria Teresa. Volume II: Cultura e Società. Bologna: Il Mulino, 1982. 
SEELAENDER, Airton Cerqueira-Leite. A Polícia e o Rei-Legislador. In: BITTAR, Eduardo. História do Direito Brasileiro: Leituras da Ordem Jurídica Nacional. São Paulo: Atlas, 2003.

. Notas sobre a constituição do direito público na idade moderna: a doutrina das leis fundamentais. In: Seqüência: estudos jurídicos e políticos. Florianópolis: Boiteux, 1980 - Semestral.

TARELLO, Giovanni. Il "problema penale" nel secolo XVIII. In: TARELLO, Giovanni (org.). Materiali per una Storia della Cultura Giuridica. Vol. V. Genova: Il Mulino, 1975.

. Montesquieu Criminalista. In: TARELLO, Giovanni (org.). Materiali per una Storia della Cultura Giuridica. Vol. V. Genova: Il Mulino, 1975. . Storia della cultura giuridica moderna: assolutismo e codificazione del diritto. Bologna: Il Mulino, 1999.

VENTURI, Franco. Introduzione. In: BECCARIA, Cesare. Dei Delitti e delle Pene. Com uma raccolta di lettere e documenti relativi alla nascita dell'opera e alla sua fortuna nell'Europa del Settecento. A cura di Franco Venturi. Torino: Einaudi, 1958.

. Utopia e Riforma nell'Illuminismo. Torino: Einaudi, 1989.

VERRI, Pietro. Considerazioni sul commercio dello Stato di Milano. Milano: Università Luigi Bocconi, 1939.

VOLTAIRE. Comentários políticos. Trad. Antonio de Pádua Danesi. Rev. trad. Cláudia Berliner. São Paulo: Martins Fontes, 2001.

WOOLF, Stuart J.; CARACCIOLO, Alberto; BADALONI, Nicola; VENTURI, Franco. Storia d'Italia. Vol. 3. Dal primo Settecento all'Unità. Torino: Einaudi, 1978.

ZAFFARONI, Eugenio Raul; PIERANGELI, José Henrique. Manual de direito penal brasileiro. Volume 1: parte geral. 6. ed. São Paulo: Revista dos Tribunais, 2006.

ZARONE, Giuseppe. Etica e politica nell'utilitarismo di Cesare Beccaria. Napoli: Istituto Italiano per gli Studi Storici, 1971.

ZORZI, Renzo. Cesare Beccaria. Il Drama della Giustizia. Milano: Bollati Borighieri, 1996. 